\title{
An assessment of aquatic radiation pathways in Ireland
}

\author{
L. Currivan ${ }^{1}$, K. Kelleher ${ }^{1}$, O. Hanley ${ }^{1}$, L. McKittrick ${ }^{1}$, \\ F. Clyne ${ }^{2}$ and D. Pollard ${ }^{1}$ \\ ${ }^{1}$ Radiological Protection Institute of Ireland, 3 Clonskeagh Square, Clonskeagh Road, \\ Dublin 14, Ireland \\ ${ }^{2}$ The Centre for Environment, Fisheries \& Aquaculture Science, Lowestoft Laboratory, \\ Pakefield Road, Lowestoft, NR33 OHT, UK
}

\begin{abstract}
Members of the public are exposed to radiation because of where they live and their habits bring them into contact with sources of radiation. They may be exposed directly by the source, by direct irradiation or inhalation of released activity or indirectly by exposure to contaminated environmental materials such as food. Consequently habit data are an essential part of dose assessment for members of the public [1]. Previously no detailed surveys had been undertaken in Ireland of habit data relevant to the assessment of doses to the population from radioactivity in the marine environment. Instead RPII dose assessments were made on the basis of assumed or notional data inferred from habit surveys undertaken elsewhere and from national average consumption figures. Following a tender process the Centre for Environment, Fisheries \& Aquaculture Science, Cefas, UK, were commissioned to undertake a Habits Survey. Its report [2] provides an assessment of aquatic radiation exposure pathways in Ireland relating to anthropogenic radioactivity in the Irish Sea.
\end{abstract}

\section{BACKGROUND}

The Radiological Protection Institute of Ireland, RPII, implements a comprehensive programme to monitor radioactivity in the Irish marine environment. The primary objective of this monitoring programme is to assess the exposure to the Irish population from anthropogenic radioactive contamination of the Irish marine environment [3].

Anthropogenic radioactivity in the marine environment can result in exposure to the population via consumption of contaminated seafood and via external radiation exposure e.g. when walking on beaches, swimming in the sea, etc. Dose assessments are made by combining marine monitoring data with habit data such as fish and shellfish consumption rates, beach occupancy rates and occupational exposure such as fishermen handling fishing gear. The RPII monitoring programme has consistently shown that the dominant pathway by which anthropogenic radioactive contamination of the marine environment results in radiation exposure of the Irish population is the consumption of fish and shellfish from the Irish Sea. This exposure is primarily due to authorised discharges from the Sellafield nuclear reprocessing plant, UK, into the Irish Sea.

Previously no detailed surveys had been undertaken in Ireland to determine the habits data used to assess radiation doses from radioactivity in the marine environment. Instead dose assessments, primarily concerned with the dose ingested, were made on the basis of assumed data inferred from habit surveys undertaken elsewhere or from national average consumption figures. Consequently, the RPII decided to undertake a Habits Survey concentrating on the north east coastline, the Irish coastline closest to the Sellafield nuclear reprocessing plant, in order to improve the accuracy of its dose assessments and to include other exposure pathways.

Following a tender process the Centre for Environment, Fisheries \& Aquaculture Science (Cefas), UK, were commissioned to undertake the Habits Survey. 

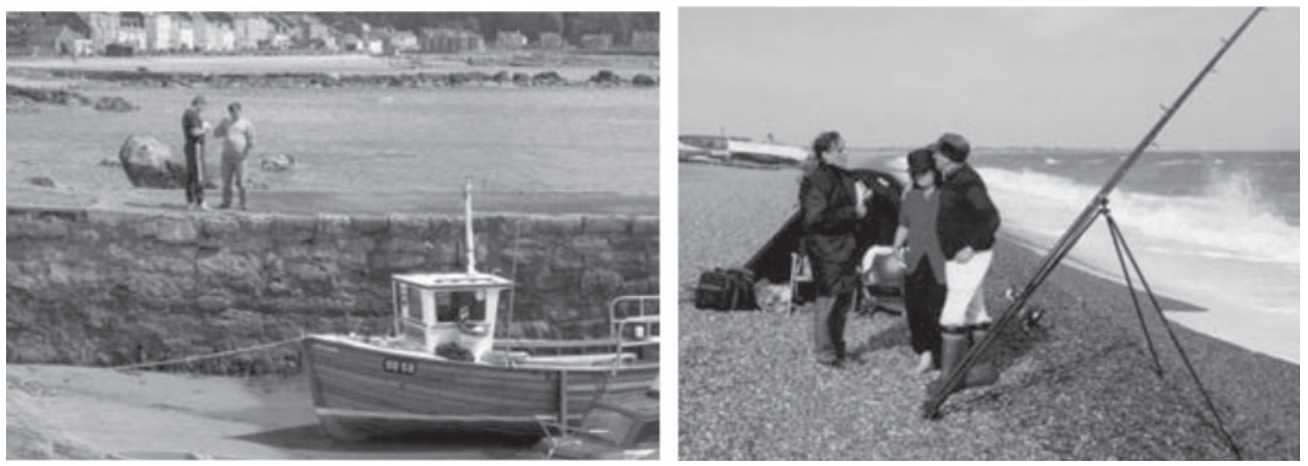

Figure 1. Interviewing fishermen and anglers.

\section{THE SURVEY}

\subsection{Aim}

The aim of this survey was to identify the critical pathways by which people living in Ireland are exposed to ionising radiation as a result of discharges of radioactive materials into the Irish Sea and to collect quantitative information on fish consumption, beach occupancy, etc. to allow realistic dose assessments to be made.

\subsection{Method}

In preparation for the survey a review of published data on habits, consumption trends and dose assessments relevant to marine exposure pathways in the survey area were conducted. A meeting was held between RPII and Cefas representatives, during which this information was presented and the survey areas were agreed. These discussions provided an outline of the main aims of the survey and highlighted issues that required special attention. In addition, information was gathered relevant to the aquatic exposure pathways in the survey areas. This included contacting people and organisations with a local knowledge of the survey area.

The survey fieldwork was carried out in July 2008 using techniques described by Leonard et. al. [4]. During this time, people were interviewed to obtain information on any aspects relevant to aquatic exposure pathways, figure 1 . The survey team targeted potential high-rate consumers of seafood, and individuals undertaking activities on intertidal areas and at sea. The habits of 535 individuals were recorded with a total of twenty-one person-days spent conducting interviews.

\subsection{Survey areas}

The survey area along the north-east coast of Ireland included the coastline from Clogherhead to Omeath in Co. Louth and commercial fishing ports north of Dublin, figure 2. The terrain is a mixture of rocky cliffs, mud flats, sand and shingle beaches, sand flats, salt marshes and rocky headlands. This is the area in which the highest levels of radioactivity attributable to Sellafield are observed [3].

\subsection{The habits survey report}

The Habits Survey report provides an assessment of aquatic radiation exposure pathways in Ireland relating to artificial radioactivity in the Irish Sea. It comprises:

- The results of the Habits Survey undertaken on the north-east coast of Ireland,

- An ingested dose assessment calculated from the Habits Survey data and RPII monitoring data, 

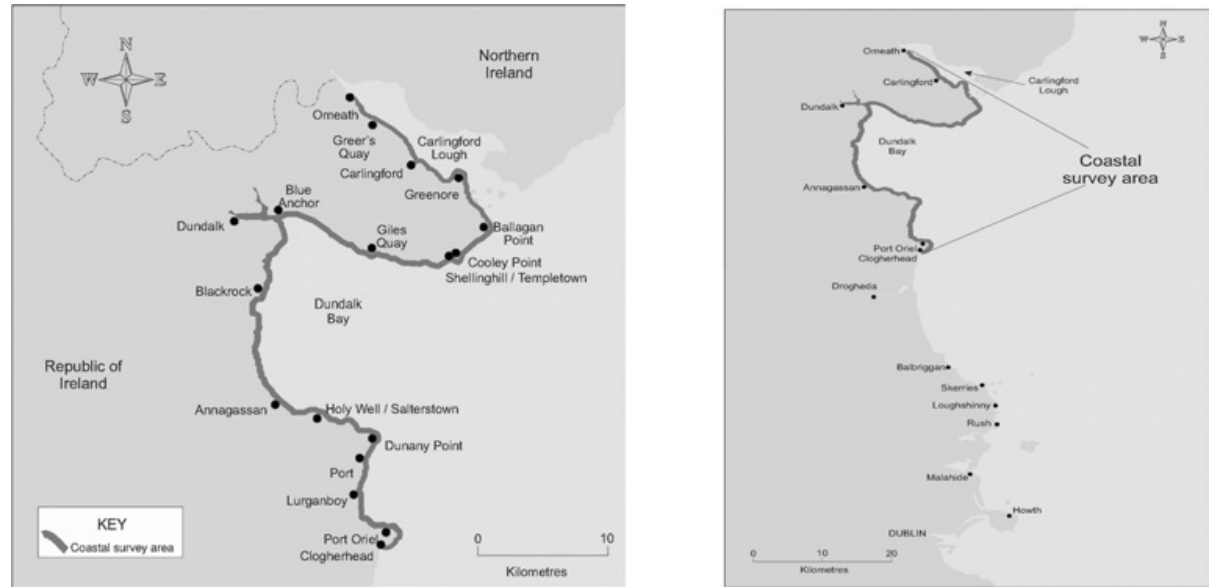

Figure 2. The coastal survey area and harbours between Carlingford and Howth.

- Recommendations for changes to the current marine monitoring programme for the east coast of Ireland conducted by the RPII.

\section{DATA HANDLING}

Data were aggregated into groups with broadly similar attributes. For example, for aquatic food consumption, all crustacean species were grouped together as 'crustaceans'. In addition, data were structured into age groups as different dose coefficients apply to different ages. The age groups and their relevant age ranges are based on the recommendations in ICRP 72 [5].

High rates of consumption, occupancy and handling have been calculated using the 'cut-off' method described by Hunt et.al [6] and the 97.5th percentile rates. The 'cut-off' method involves taking the arithmetic mean of the maximum observed rate and all observed rates within a factor of 3 of the maximum value (termed the lower threshold value). The use of percentiles agrees with precedents used in risk assessment of the safety of food consumption [7]. For ease of presentation the term 'high-rate group' is used to represent the value derived by the cut-off method.

\section{SUMMARY OF FINDINGS}

The mean consumption rates for the adult high-rate groups:

- Fish $26 \mathrm{~kg} / \mathrm{y}$

- Crustaceans $9.7 \mathrm{~kg} / \mathrm{y}$

- Molluscs $25 \mathrm{~kg} / \mathrm{y}$

- Seaweed $0.50 \mathrm{~kg} / \mathrm{y}$
64 high-rate consumers

22 high-rate consumers

4 high-rate consumers

1 high-rate consumer

The species breakdown for each high-rate group, rounded to the nearest 5\%:

- Fish

- Crustaceans

- Molluscs

- Seaweed
$20 \%$ mackerel, $15 \%$ haddock and $65 \%$ other species

$35 \%$ brown crab, $30 \%$ lobster and $30 \%$ nephrops

$75 \%$ mussels, $10 \%$ pacific oysters and $10 \%$ winkles

$100 \%$ dulse (Palmaria palmata) 
Table 1. Committed effective doses from artificial radionuclides due to the consumption of fish and shellfish landed at north-east ports, 2007-2009.

\begin{tabular}{|l|c|c|c|}
\hline Seafood Consumer & $2007(\mu \mathrm{Sv})$ & $2008(\mu \mathrm{Sv})$ & $2009(\mu \mathrm{Sv})$ \\
\hline Typical Consumer & 0.16 & 0.09 & 0.09 \\
\hline Heavy consumer & 0.74 & 0.37 & 0.38 \\
\hline Group A, commercial & 0.29 & 0.23 & 0.24 \\
\hline Group B, oyster and mussel farmers & 0.47 & 0.40 & 0.44 \\
\hline
\end{tabular}

The mean occupancy rates over intertidal substrates for the adult high-rate groups were:

- $360 \mathrm{~h} / \mathrm{y}$ over mud 15 oyster farmers

- $520 \mathrm{~h} / \mathrm{y}$ over mud and sand

- $50 \mathrm{~h} / \mathrm{y}$ over mud, sand and stones

- $100 \mathrm{~h} / \mathrm{y}$ over rock

- $410 \mathrm{~h} / \mathrm{y}$ over sand

-

- $640 \mathrm{~h} / \mathrm{y}$ over sand and stones

1 commercial winkle collector

1 walker

1 angler

10 oyster farmers, 7 dog walkers, 1 angler/dog walker, and 1 individual undertaking watersports preparation 1 winkle collector, 4 shore anglers and 4 dog walkers

The mean handling rates of fishing gear and catch, and sediment, for the adult high-rate groups:

- $2500 \mathrm{~h} / \mathrm{y}$ handling commercial fishing gear and catch gear and catch, and 2 fishermen handling dredge gear and catch

- $730 \mathrm{~h} / \mathrm{y}$ handling sediment oyster farmers 31 fishermen handling trawl

2 commercial winkle collectors and 15

The mean occupancy rates of activities in and on water for the adult high-rate groups were:

- $330 \mathrm{~h} / \mathrm{y}$ in water 16 windsurfers/kayakers, 3 kite-surfers, 3 swimmers and 1 watersports instructor

- $3100 \mathrm{~h} / \mathrm{y}$ on water 52 commercial fishermen

\section{DOSE ASSESSMENT}

The Habits Survey identified two critical groups, referred to as Group A and Group B [8]. Group A were a group of commercial fishermen who consume large amounts of fish and crustaceans. Group B were commercial oyster and mussel farmers who consume large amounts of molluscs.

The monitoring data used in the dose calculations are taken from those samples collected as part of the RPII's routine monitoring programme. Prior to calculating the dose, the monitoring data were weighted to take account of consumption of different fish and mollusc species, and then normalised as some species are not covered by the monitoring programme. Activity concentrations in all crustacean species are represented by the concentrations of radionuclides in prawns, as these were the only crustacean monitoring data available.

The committed effective dose through consumption of seafood to members of groups A and B for years 2007 to 2009 can be seen in Table 1. The corresponding doses to RPII notional typical and heavy consumers are shown for comparison purposes. The notional typical consumer $(40 \mathrm{~g}$ fish per day and $5 \mathrm{~g}$ shellfish per day) was intended to represent the dose received to an average seafood consumer while the notional heavy consumer ( $200 \mathrm{~g}$ fish per day and $20 \mathrm{~g}$ shellfish per day) was intended to represent a conservative estimate of the dose to a high rate consumer. It is reassuring to note that the doses received by members of the two critical groups identified in this survey fall within the range previously estimated by the RPII on the basis of notional consumer groups.

In 2009, the dose due to ingestion to Group A consumers was found to be $0.24 \mu \mathrm{Sv}$ and accounts for less than $0.03 \%$ of the annual dose limit of $1000 \mu \mathrm{Sv}$ for members of the public from practices 
Table 2. Key recommendations arising from the Habits Survey.

\begin{tabular}{|l|l|}
\hline $\begin{array}{l}\text { Recommendation } \\
\text { Some significant consumption of haddock was identified } \\
\text { in the Habits Survey and as such could replace whiting, } \\
\text { as it is a similar demersal species }\end{array}$ & $\begin{array}{l}\text { RPII Response } \\
\text { Haddock has replaced whiting in the } \\
\text { RPII monitoring programme }\end{array}$ \\
\hline $\begin{array}{l}\text { Herring samples could be discontinued since herring was } \\
\text { consumed in very low quantities and monitoring of } \\
\text { pelagic fish species is adequately covered by mackerel }\end{array}$ & $\begin{array}{l}\text { Collection of herring has been } \\
\text { discontinued }\end{array}$ \\
\hline $\begin{array}{l}\text { A lobster sample could be introduced as lobsters were } \\
\text { consumed in significant quantities and they are known to } \\
\text { bioaccumulate technetium-99 }\end{array}$ & $\begin{array}{l}\text { Lobster sampling has been re-introduced } \\
\text { in the RPII monitoring programme }\end{array}$ \\
\hline $\begin{array}{l}\text { Molluscs tend to contain higher concentrations of some } \\
\text { radionuclides (e.g. Pu actinides) than crustaceans and fish, } \\
\text { and significant consumption of winkles was }\end{array}$ & $\begin{array}{l}\text { Winkles are now included in the } \\
\text { monitoring programme }\end{array}$ \\
$\begin{array}{l}\text { identified. Therefore a sample of winkles could be } \\
\text { introduced }\end{array}$ & $\begin{array}{l}\text { Since individuals were identified with high intertidal } \\
\text { occupancy rates, for example on Greenore and } \\
\text { Clogherhead beaches, it may be necessary to introduce } \\
\text { gamma dose rate monitoring of intertidal areas }\end{array}$ \\
$\begin{array}{l}\text { Similarly, as individuals with high rates of handling } \\
\text { fishing gear and catch were identified, beta dose rates } \\
\text { from fishing gear could be investigated }\end{array}$ & $\begin{array}{l}\text { Sediment samples are collected at the } \\
\text { Carlingford site in order to assess the } \\
\text { dose arising from exposure over } \\
\text { sediment to the Group A and Group B individuals }\end{array}$ \\
\hline
\end{tabular}

involving controllable sources of radiation [9]. The dominant contributors to this dose are caesium$137(58 \%)$ and technetium-99 (33\%). For the Group B consumers the dose arising from ingestion is $0.44 \mu \mathrm{Sv}$ and accounts for less than $0.05 \%$ of the annual dose limit to members of the public of $1000 \mu \mathrm{Sv}$. The dominant contributors to this dose are plutonium-238, 239, 240 (36\%), technetium-99 $(35 \%)$ and americium-241 (18\%). The higher dose to this group may be attributed to the relatively high dose coefficients for plutonium-238, 239, 240 and americium-241.

These doses may also be compared with the average annual dose to a person in Ireland from all sources of radioactivity of $3950 \mu \mathrm{Sv}$ [10].

\section{RECOMMENDATIONS AND RESPONSE}

The Habits Survey report broadly endorses the RPII's marine monitoring programme and recommends that it be continued in its current form. The report makes a number of recommendations based on the findings of this survey as follows, Table 2:

As recommended, an assessment of some external radiation exposure pathways relevant to this Habits Survey has been undertaken. The pathways considered were exposure over sediment, inhalation of sea-spray and from fishing gear. Dose assessments were carried out with RPII monitoring data using the "consequences of routine releases of radionuclides to the environment" (CREAM) methodology [11-13]. It is intended that this methodology be used for future assessments.

Results from these assessments show that for Group A individuals, the dose arising from handling fishing gear is $0.046 \mu \mathrm{Sv}$ with the total dose remaining at $0.03 \%$ of the annual dose limit of $1000 \mu \mathrm{Sv}$ for members of the public. For the Group B individuals, the dose from inhaled sea-spray, exposure over sediment and from fishing gear is $0.359 \mu \mathrm{Sv}$ with the total dose accounting for $0.08 \%$ of the annual dose limit of $1000 \mu \mathrm{Sv}$ for members of the public.

In conclusion, the doses incurred by the Irish public as a result of artificial radioactivity in the environment are small when compared to national dose limits or natural radiation doses. The doses received from exposure pathways over sediment, from fishing gear and from inhalation of sea-spray represent a small fraction of the annual dose limit of $1000 \mu \mathrm{Sv}$ for members of the public from practices 
involving controllable sources of radiation. It must also be emphasised that the levels of radioactive contamination present in the marine environment do not warrant any modification of the habits of people in Ireland, either in respect of consumption of seafood or any other use of the amenities of the marine environment

\section{References}

[1] Smith K.R. and Jones A.L., Generalised habit data for radiological assessments (NRPB, Chilton, 2003).

[2] Clyne F.J., Garrod C.J., Jeffs T.M. and Jenkinson S.B., An assessment of aquatic radiation pathways in Ireland, 2008 (The Centre for Environment, Fisheries \& Aquaculture Science, Lowestoft, 2008).

[3] McGinnity P., Currivan L., Dowdall A., Fegan M., Hanley O., Hayden E., Kelleher K., McKittrick L., Somerville S., Wong J. and Pollard D., Radioactivity Monitoring of the Irish Environment 2009 (Radiological Protection Institute of Ireland, Dublin, 2010).

[4] Leonard D.R.P., Hunt G.J. and Jones P.G.W., "Investigations of individual radiation exposures from discharges to the aquatic environment: the technique of habit surveys", Third International Symposium on Radiological Protection - Advances in Theory and Practice, Inverness, 6-11 June 1982 (The Society of Radiological Protection, 1982) pp. 512-517

[5] ICRP, Age-dependent doses to members of the public from intake of radionuclides (ICRP, Oxford, 1996).

[6] Hunt G. J., Hewett C. J. and Shepherd, J.G., Health Physics Volume 43 (1982) 875-889.

[7] Cutts D., Gaunt M., Hunt H., Roche P., Thorne M., Titley J., Smith R. and Webbe-Wood D., Position paper on the collection and use of habits data for retrospective dose assessments (National Dose Assessment Working Group, 2005)

[8] ICRP, Assessing the dose of the representative person for the purpose of radiological protection of the public and the optimisation of radiological protection (ICRP, Oxford, 2007)

[9] Radiological Protection Act, 1991 (Ionising Radiation) Order, 2000, Statutory Instrument No. 125 of 2000 (Stationery Office, Dublin)

[10] Colgan P.A., Organo C., Hone C., Fenton D., Radiation doses received by the Irish population (Radiological Protection Institute of Ireland, Dublin, 2008)

[11] Hunt G.J., Radiat. Prot. Dosim. Volume 8 (1984) 215-224.

[12] Howorth J.M., Eggleton A.E., Studies of environmental radioactivity in Cumbria. Part 12: Modelling of sea-to-land transfer of radionuclides and an assessment of the radiological consequences, (UKAEA, 1988)

[13] Simmonds J., Lawson G. And Mayall A., Methodology for assessing the radiological consequences of routine releases of radionuclides to the environment (European Commission, 1995) 